\title{
- Current Issue Updates
}

\section{Dr. Sachin Ingle}

IJCRR

Section: Healthcare

ISI Impact Factor

(2019-20): 1.628

IC Value (2019): 90.81

SJIF (2020) $=7.893$

(c) (i) (8)

Copyright@IJCRR
Professor, MIMSR Medical College, Maharashtra, India.

Email:dr.sachiningle@gmail.com.
Indeed it's a proud moment for me to release the current issue of IJCRR with extremely useful academic fist for global medical researchers and post graduates in medical field. Hope all the readers like this issue whole heatedly in view of outstanding selection of articles by my editorial team and scholar reviewers contributing from worldwide regions.

The opinion article by Anoop Kalsingal Covid -19 : plasma therapy and stem cell therapy is extremely useful in treatment of Covid-19 worldwide.

Letter to editor by Debasish Kar Mahapatra on awareness in women workers in hen poultry is very useful to all women labours in poultry farming.

An article by Reham Mohammad Kharabah et al. on prevalence of premenstrual syndrome and its influence on job performance of nurses is useful in hospital administration and management.

Article by Sujatha Baskaran to evaluate the sleep pattern in children with and without developmental co-ordination gives an idea to pediatric physiologists.

Antibiogram and isolation of $\mathrm{S}$. aureus from the urinary tract infections by Basavaraj C. is useful for microbiology read- ers, post graduates in microbiology and urologists to plan the management.

Article by Shinde Rekha resuscitation in Ayurveda for newborn is useful for post graduates of Ayurveda working in pediatrics.

Review of Viparit Lajjalu and its effects on sperms is useful in studies related to male infertility.

Histomorphological spectrum of neoplastic lesions of kidney by Nalini Modepalli is nice article for pathology readers and post graduates in pathology.

The study of orally administered molotonin and clonidine for attenuation of hemodynamic response during laryngoscopy and edotracheal intubation in gastrointestinal surgeries is useful to gastroenterologists and gastrointenstinal surgeons.

Overall all articles received are highly peer reviewed, good quality articles useful for global researchers, medical students and faculties.

Hope all of you like this up to high extent and learn new things in respective fields.

All of you stay home, stay safe, take care in COVID-19 wave.

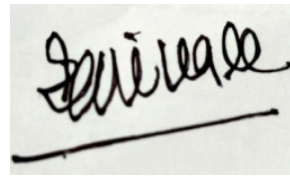

Dr. Sachin B. Ingle

Editor In chief, IJCRR 